\title{
Negative skin friction pile concepts with soil-structure interaction
}

1 Siew Ann Tan

Associate Professor and Professional Geotechnical Engineer,

Department of Civil \& Environmental Engineering, National University

of Singapore, Singapore (corresponding author: ceetansa@nus.edu.sg)
2 Bengt H. Fellenius

Consulting Professional Geotechnical Engineer, Sidney, BC, Canada
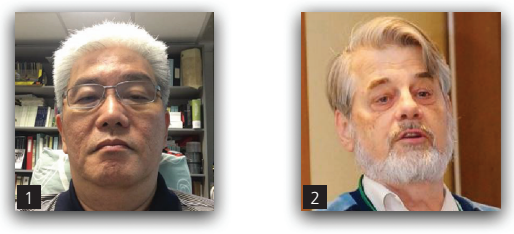

Code-based design of piles with negative skin friction (NSF) considers the NSF force (the drag force) as a load to be imposed on the pile as an unfavourable design action. These codes - for example Singapore Code of Practice CP4, UK Standard BS EN 8004:1986 and the recent Eurocode 7 (EC7) (BS EN 1997-1:2004) - would indirectly factor up the value of the drag force while at the same time disregard the shaft resistance above the neutral plane and factor down the positive shaft resistance below the neutral plane. Thus, the pile design in very deep soft clays typical of Singapore and Asian coastal plains will lead to very conservative pile lengths to meet the code requirements. The Fellenius unified pile design method recognised this deficiency, and it allows for better pile design with NSF taking into account the need for both force and settlement equilibrium between the pile and the soil. Fortunately, EC7 also allows for interactive pile-soil analysis using modern finite-element method tools that can optimise pile design for NSF, in particular when the remaining consolidation settlements around the piles are relatively small. This paper will compare these methods, provide insights into the proper understanding of NSF effects on pile behaviour and recommend the way forward for rational and economical pile design in settling soils.

\section{Notation}

EA pile axial rigidity

$F_{\mathrm{S}} \quad$ geotechnical factor of safety (usually taken as $2 \cdot 5$ )

$P_{\mathrm{c}} \quad$ dead load (DL) plus live load (LL) to be carried by each pile

$Q_{\mathrm{al}} \quad$ pile allowable load

$Q_{\mathrm{b}} \quad$ pile ultimate toe bearing resistance

$Q_{\text {sn }}$ accumulated negative skin friction force, the drag force at neutral point

$Q_{\text {sp }} \quad$ pile ultimate positive shaft resistance below the neutral plane

$\eta \quad$ degree of mobilization typically $0 \cdot 67$, although $1 \cdot 0$ may be used in specific cases

\section{Introduction}

The current state of practice for the design of piles is to place emphasis on the pile as a capacity determination problem. This entails the determination of the pile-bearing capacity (or resistance) by means of rational theory and verified by a maintained static loading test to failure. Once the capacity is determined, the working load to assign to the pile in the design can be estimated as the available resistance divided by some form of factor to ensure that, at working stress conditions, the pile is not loaded to a level anywhere near its capacity. This means that it is assumed that the pile settlements then remain small - that is, it stays within acceptable limits (usually taken as $<25 \mathrm{~mm}$ ).

Prior to Eurocode 7 (EC7; BS EN 1997-1:2004 (BSI, 2004)), BS EN 8004:1986 (BSI, 1986) and CP4 (Spring Singapore, 2003) used a gross, all-encompassing, global factor-of-safety approach for pile design. With EC7, the limit state approach instead employs partial factors on both the action and the resistance side of the equations, factoring up the unfavourable actions and factoring down the favourable resistance in one of the three design approaches (DA1, DA2 or DA3). For Singapore, the authors have adopted DA1, combinations 1 and 2, in line with the UK practice.

\section{Deficiency of current codes on pile design with negative skin friction}

When the design codes treat pile design as a capacity problem, it often follows that the negative skin friction (NSF)-induced force in the pile is treated as an unfavourable load for the pile. For example, BS EN 8004:1986 (as well as CP4) defines NSF as a downwards frictional force applied to the shaft of a pile caused by 
the consolidation of compressible strata - for example, under recently placed fill. It adds the note that this has the effect of increasing the force in the pile and, ostensibly, therefore, reducing the bearing capacity. Thus, it is implied that the NSF can act in such a way as to cause a bearing failure of the pile. Clearly, this is a faulty concept that is contrary to reality.

\section{Typical example of using CP4}

The code used in Singapore prior to 1 April 2015, is CP4, which is a near copy of BS EN 8004:1986 with some modifications. The key equation in CP4 governing NSF pile design is in clause 7.3.6 as follows.

For geotechnical design, the allowable load on a pile subject to NSF in the long term $\left(Q_{\mathrm{al}}\right)$ is given by the following general equation

1. $Q_{\mathrm{al}}=\frac{Q_{\mathrm{b}}+Q_{\mathrm{sp}}}{F_{\mathrm{s}}} \geq P_{\mathrm{c}}+\eta Q_{\mathrm{sn}}$

$Q_{\mathrm{b}}$ is the ultimate toe bearing resistance, $Q_{\mathrm{sp}}$ is the ultimate positive shaft resistance below the neutral plane (NP), $F_{\mathrm{s}}$ is the geotechnical factor of safety (usually taken as $2 \cdot 5$ ), $P_{\mathrm{c}}$ is the dead load (DL) plus live load (LL) to be carried by each pile, $Q_{\mathrm{sn}}$ is the accumulated NSF force, the drag force, and $\eta$ is the degree of mobilisation, typically $0 \cdot 67$, although $1 \cdot 0$ may be used in specific cases.

It is assumed in Equation 1 that the pile resistances $Q_{\mathrm{b}}$ and $Q_{\mathrm{sp}}$ and the drag force $Q_{\mathrm{sn}}$ are determined using unfactored soil parameters. The ' $>$ ' condition can never be fulfilled, however, and the equal condition ' $=$ ' is valid for only an $\eta$-degree of unity. And, of course, were the assigned $P_{\mathrm{c}}$ to be changed, the $Q_{\mathrm{sp}}$ and $Q_{\mathrm{sn}}$ would change too, as would the location of the NP. That is, Equation 1 is applicable only for a specific situation where the interrelations between the applied DL, $P_{\mathrm{c}}$ and the environmental loads $Q_{\mathrm{sp}}$ and $Q_{\mathrm{sn}}$ are recognised and recalculated for every change in $P_{\mathrm{c}}$. Moreover, the $Q_{\mathrm{b}}$ is an undefined component that depends entirely on the magnitude of the pile toe penetration into the soil.

Even if Equation 1 would represent the actual long-term condition for a pile, it epitomises a challenging situation when there is a case of more than 20-m-thick soft clays above the stiffer competent founding soils. Worse still is the common Singapore situation where there is a very thick, often more than $20 \mathrm{~m}$, reclamation sand fill placed on top of a still-consolidating layer of soft marine clay. In such situations, it is not uncommon to have very long piles socketed several metres into the competent soil below the soft clays in order to satisfy Equation 1, even for the case of carrying a small permanent load of $<300 \mathrm{kN}$ for each pile. This is particularly because the inequality built into the calculations using Equation 1 reduces the positive shaft friction available above the NP which actually assists in resisting the load applied to the pile.

Moreover, Equation 1 does not recognise that the LL and drag force cannot exist at the same time. This implies that a typical
Singapore pile designed for shaft bearing according to Equation 1 would need to be $50 \%$ longer than a pile for which the design would realise that for ultimate condition, where there is no NSF and the pile is supported along its entire length. Furthermore, it is often the case that on finding the drag force to be excessive, the design pile length is increased without the proper recalculation of Equation 1 for the changed condition. A proper recalculation would show that the lengthening is not sufficient, because it can never be. The longer pile will receive a large drag force and, according to Equation 1, need to be installed even deeper. There is no end to it, unless a substantial toe resistance can be built up. Then, after adding the pile length, the analysis would likely show that the maximum load in the pile (at the neural plane) exceeds the axial structural strength of the pile.

As Equation 1 is used in current practice, it is, knowingly or not, applied with disregard from what it really states - the ' $<$ ' sign is believed to be correct and no recalculation is made after the first run. Clearly, this is not commensurable with good practice in the 21 st century.

\section{Unified pile design}

The second author (Fellenius, 1984, 1988) recognised the fallacy of treating NSF as an unfavourable action on a pile in settling soils and proposed the unified pile design concept, further refined over the years with the support of many high-quality field research data based on instrumented piles from around the world. Much of these publications are summarised and discussed in the online book by Fellenius (2015) titled The Red Book - Basics of Foundation Design, freely available at his website.

The most important contribution is the recognition that the NSF issue is not a pile capacity problem, but an issue of pile movements and settlements with respect to a settling soil.

Placing loads on a pile causes downward movements of the pile head due to

(a) 'elastic' compression (shortening) of the pile

(b) load transfer movement - refers to the movement response of the soil at the pile toe

(c) settlement below the pile toe due to the increase of stress in the soil (this is only of importance for large pile groups and where there are soil layers below the piles that are relatively compressible).

A drag force will only directly cause movement due to point (a) (the elastic compression), while it may be argued that point $(b)$ is also at play, because the stiffness of the soil at the pile toe is an important factor here; it is mostly the down drag (pile settlement due to the settling soil surrounding the pile dragging down the pile) that governs (i) the pile toe movement, (ii) the pile toe load and (iii) the location of the NP in an interactive 'unified' process, to achieve both force and settlement equilibrium in the pile/soil system. The drag force on its own cannot cause settlement due to 
point $(c)$, because there has been no stress change in the soil below the pile toe due to drag force itself.

Therefore, the drag force cannot and does not diminish the geotechnical capacity in piles. Drag force (plus DL) is a matter for the pile structural strength design. The main issue or question is: will settlements occur around the piles that can cause excessive down drag? The approach is expressed in the unified pile design method, which is a method based on the interaction between forces and pile movements.

(a) The unified pile design method as applied to single piles and small pile groups is a three-step approach involving the following principles. The DL plus LL must be smaller than the pile capacity divided by an appropriate code factor of safety. The drag force is not included when designing against the bearing capacity.

(b) The DL plus the drag force must be smaller than the structural axial strength divided with appropriate factor of safety applicable to structural condition. The LL is not included because the LL and drag force cannot coexist.

(c) The settlement of the pile (pile group) must be smaller than the acceptable limiting value. The LL and drag force are not included in this analysis. The load from the structure does not normally cause much settlement, but the settlements due to other causes that cause large stress changes below pile toe can be large.

The principles of the mechanism that demonstrate the concepts mentioned earlier are illustrated in Figure 1. The distribution of load at the pile cap is governed by the load transfer behaviour of the piles. The design pile can be said to be the average representative single pile. However, the loads can differ considerably between the piles depending on toe resistance, length of piles and so on.

The location of the NP is the point along the pile shaft where the pile movement and the soil settlement are the same value (no relative movement between pile and soil). Above the NP, the soil settles more with respect to the pile, so there is NSF. Below the $\mathrm{NP}$, the pile moves downwards relative to the soil, thus developing positive shaft friction (PSF). The NP is the result of soil-structure interactions, to find the force balance and settlement equilibrium.

At equilibrium, the NP will be in such a position that the DL plus NSF will balance the PSF below the NP plus the mobilised toe resistance $R_{\mathrm{t}}$. The mobilised toe resistance is a function of the net pile toe movement (or penetration) into the base soil such that it develops sufficient toe resistance to provide the required force equilibrium. If the result - by design or by mistake - is that the NP lies in or above a compressible soil layer, the pile group will settle even if the total resistance factor of safety appears to be acceptable by design.

Therefore, it is not difficult to realise that any fictitious force equilibrium equations that introduce unequal partial factors on negative and positive shaft resistances on either side of the action/ resistance equations will contradict nature and result in a conservative design that is not economically sensible.

\section{EC7 allows for pile-soil interaction in NSF design}

The introduction of EC7 for pile design using limit state analysis with partial factors of safety for actions, materials (soils strengths) and resistances appears to suffer also the pitfalls of the unbalanced force equilibrium equations when applied to pile design with large NSF.

Realising that the NSF pile design is a settlement rather than a capacity issue should lead designers to tackle the problem from a pile movement/settlement viewpoint. Surprisingly, the relevant clauses for pile design in the UK version of EC7 - Part 1, as adopted in Singapore, appear to be more liberal than either BS EN 8004:1986 or CP4 of the past. The relevant clause is clause 7.3.2.2 (4), where the designer is given an option to design for

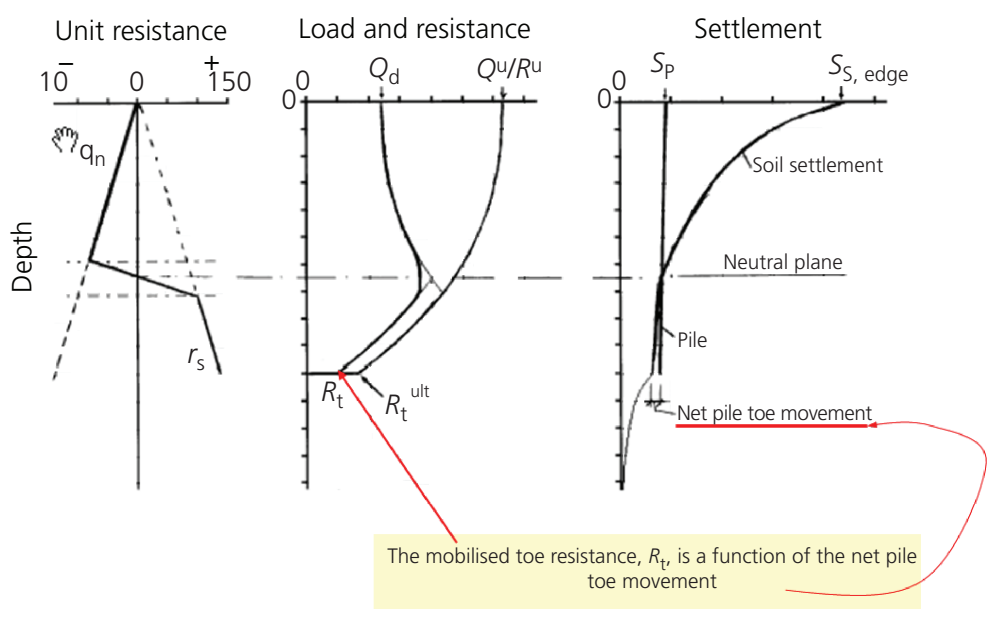

Figure 1. Diagrams to illustrate the unified soil/pile interactions

(after Fellenius (1984)) 
NSF using pile-soil interaction analysis to determine a muchreduced drag force when ground settlements around the piles are expected to be relatively small.

\section{Clause 7.3.2.2 down drag (NSF)}

1. If ultimate limit state design calculations are carried out with the drag force as an action, its value shall be maximum, which could be generated by the downward movement of the ground relative to the pile.

2. Calculation of maximum drag force should take account of the shear resistance at the interface between the soil and the pile shaft and downward movement of the ground due to self-weight compression and any surface load around the pile.

3. An upper bound to the drag force on a group of piles may be calculated from the weight of the surcharge causing the movement and taking into account any changes in groundwater pressure due to lowering of the groundwater table, consolidation or pile driving.

4. Where settlement of the ground after pile installation is expected to be small, an economic design may be obtained by treating the settlement of the ground as the action and carrying out an interaction analysis.

5. The design value of settlement of the ground shall be derived taking account of material weight and compressibility in accordance with Cl.2.4.3

6. Interaction calculations should take account of the displacement of the pile relative to the surrounding moving ground, the shear resistance of the soil along the shaft of the pile, the weight of the soil, and the expected surface loads around each pile, which are the cause of the down drag.

7. Normally, down drag and transient loading (short-term live load) need not be considered in load combinations. (BSI, 2004)

Clearly, clause sections 4 and 6 show that the code writers are fully aware that when ongoing ground settlements are small, the developed NSF will be quite small, and so the clause allows for pile/soil interaction analysis that will enable the pile design to treat the settlement of the ground as the action (instead of taking the drag force as the action) and determining a more appropriate value of NSF load to be used in the pile structural design.

This served as an indirect recognition that pile geotechnical capacity is not the primary focus; instead, pile settlement is the focus of the design. Also, subclause section 7 correctly recognised that NSF and transient LL (short-term LL) cannot coexist and should not be added in any load combinations of the design analysis. However, one must recognise that the sustained LL should be treated like DL in both pile geotechnical capacity and settlement analysis.

\section{Validation of unified design by finite-element study}

The unified pile design concept is demonstrated and validated by finite-element method (FEM) model studies of piles subject to settling soils, allowing for proper accounting of soil/structure interactions. The first set of study concerns a single pile in a settling ground using an axisymmetric Plaxis two-dimensional (2D) FEM model. The second set of studies concerns a pile group in a settling ground using Plaxis three-dimensional (3D) FEM software.

\section{Plaxis FEM model of single pile with NSF loadings}

The FEM analysis provides a very effective tool to study the pile/ soil interaction behaviour with piles subjected to NSF conditions of settling soils after the pile had been installed. The hypothetical model of such a single pile in a typical soft clay site is shown in Figure 2. This represents a typical soft ground condition of a top fill, underlain by a very thick soft clay layer, on top of a very stiff soil layer. The soil parameters and appropriate soil constitutive models are defined for each soil layer in Figure 2. The pile is a solid cylindrical concrete element with a soft dummy beam element (with axial rigidity of pile (EA) 1 million times less than actual pile EA) embedded in it to allow for the easy determination of the axial force distributions in the pile. The interaction between the pile and soil is modelled by a line interface element that adopts the linear elastic perfectly plastic Mohr-Coulomb model. The pile is installed by a wish-in-place replacement of soil by concrete material within the pile radius after the initial phase. The ground settlement is induced by applying ground surcharge loads of 10,20 and $40 \mathrm{kPa}$ for three cases studied under drained conditions (inducing complete long-term consolidation settlements around the pile). For each case, permanent sustained loads of 2, 4 and $6 \mathrm{MN}$ are applied to the pile head to simulate external loads on the pile, as in a simulated pile static loading test.

The pile responses for the various cases studied are discussed as follows. The typical case of pile DL of $4 \mathrm{MN}$ with and without ground settlements is shown in Figures 3(a)-3(c). Figure 3(a) shows the axial force distribution along the pile for the drag loads only, together with the short-term initial force distribution without drag loads, and the long-term force distribution with the fully developed drag loads. Figure 3(b) shows the long-term pile ground settlement imposed on the pile to produce the pile down drag. The pile head settlement is the combined effects of pile shortening from head loads plus NSF loads and pile toe penetration. Figure 3(c) shows the resulting unit skin friction distribution along the pile for the initial (without NSF) and the long-term (with gradual transition from NSF to PSF at the NP) conditions. Figure 3(d) shows the pile toe mobilised resistance against the toe penetration into the stiff founding strata.

The figure illustrates the effects of NSF, where the force equilibrium is achieved by a natural self-balancing process, where the NP is the point somewhere along the pile such that the pile and soil moved together, with NSF above the NP point and the PSF below the NP point. The force equilibrium is obtained as the DL plus the NSF equilibrates with the PSF and mobilised toe resistance. The toe resistance needed to achieve this balance will determine the amount of toe penetration of the pile. Clearly, there is an interdependence of the pile settlement, load transfer and load movement response to achieve both the force and settlement equilibrium of the pile/soil system, simultaneously. 
Geotechnical Research

Volume 3 Issue 4
Negative skin friction pile concepts with

soil-structure interaction

Tan and Fellenius

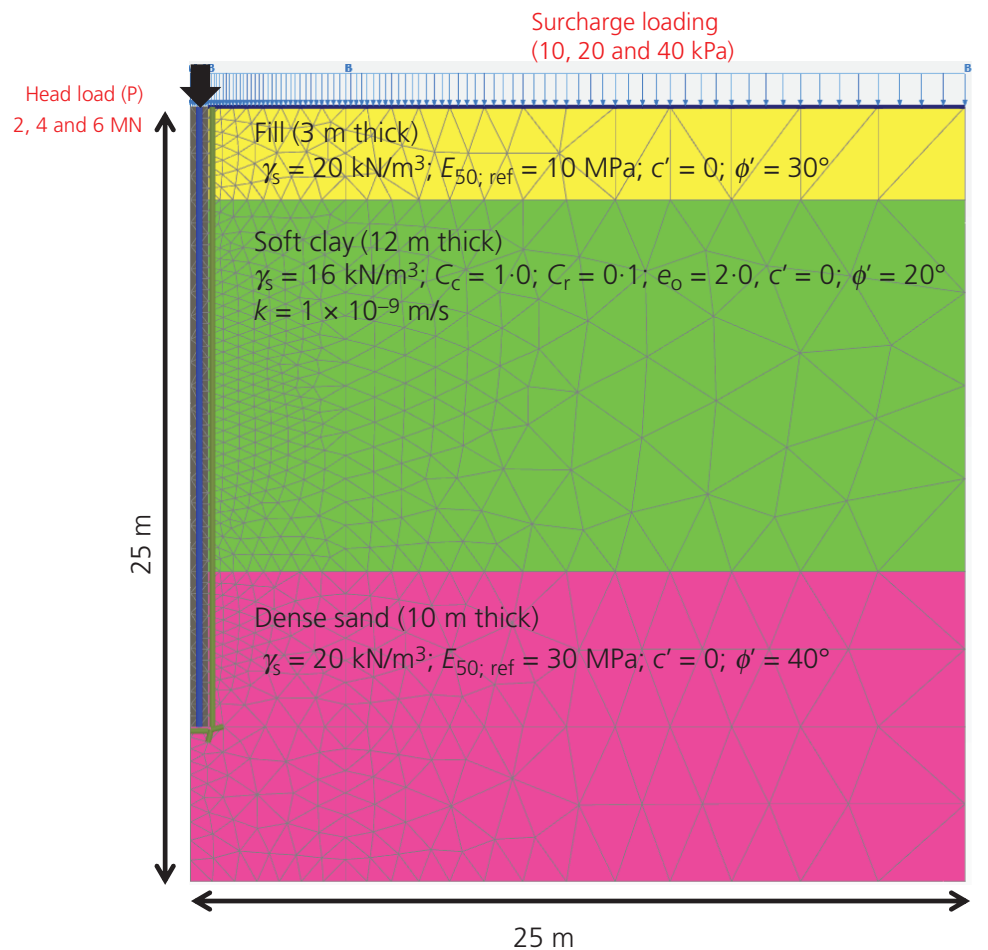

Axisymmetric model

Pile diameter, $D=1 \cdot 128 \mathrm{~m}$

Pile length, $L=20 \mathrm{~m}$

(Pile cross-sectional area $=1 \mathrm{~m}^{2}$ )

Pile concrete properties:

Concrete modulus $=30 \mathrm{GPa}$

$R_{\text {interface }}=1 \cdot 0$

$R_{\text {interface }}=0 \cdot 10$ (with bitumen

coating at fill and soft clay layer)

Dummy plate pile with EA $1 \mathrm{E} 6$

times smaller than real pile

Soil constitutive model:

Hardening soil

Figure 2. Plaxis 2D axisymmetric FEM model of single pile in settling ground

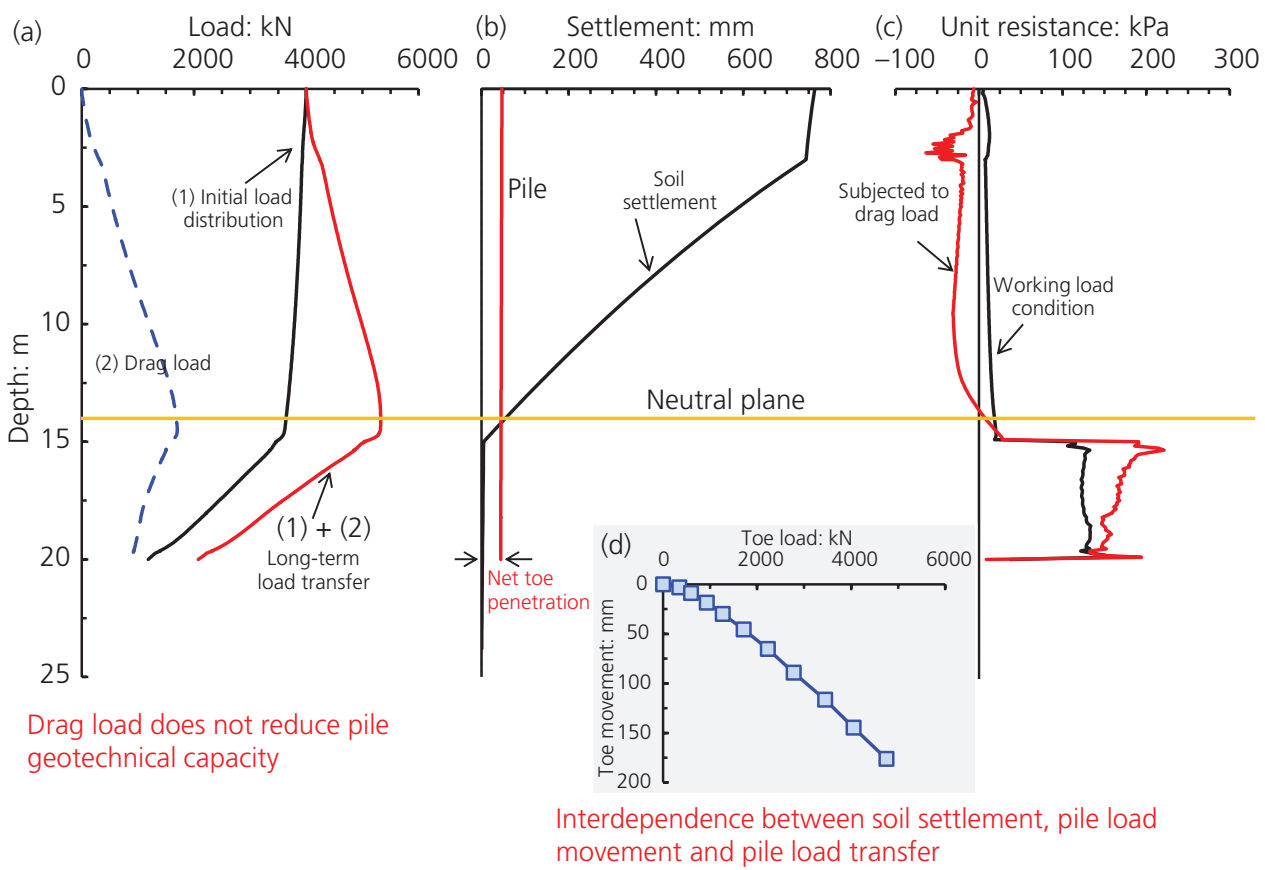

Figure 3. Typical case of $4 \mathrm{MN}$ DL with ground load of $40 \mathrm{kPa}$ (ground settles at $800 \mathrm{~mm}$ ) 
Geotechnical Research

Volume 3 issue 4
Negative skin friction pile concepts with

soil-structure interaction

Tan and Fellenius

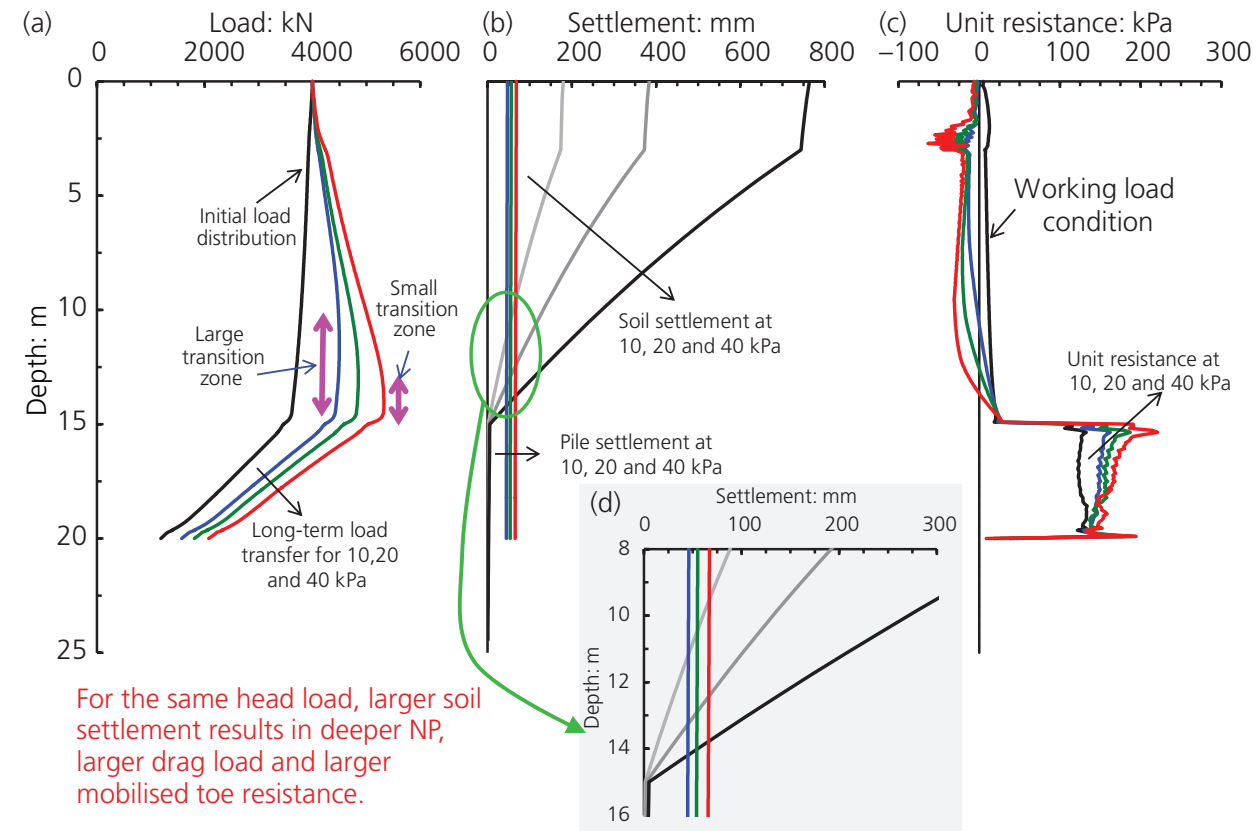

Figure 4. Cases of $4 \mathrm{MN}$ DL with ground loads of 10, 20 and $40 \mathrm{kPa}$ (ground settles at 200, 400 and $800 \mathrm{~mm}$, respectively)

Figures 4(a)-4(d) show the results of the same pile subjected to different amounts of long-term ground settlements (approximately 200, 400 and $800 \mathrm{~mm}$ ) induced by varied surface loads under drained conditions. The plots show that for the same DL, larger ground settlements resulted in a deeper NP, with larger NSF drag force and increasing mobilised toe resistance. Also, the transition zone from full NSF to full PSF is sharper and smaller as the ground settlements become larger.

Figures 5(a)-5(d) show three cases of varied DLs with the same ground settlements of about $800 \mathrm{~mm}$. It appears that, for the same ground settlements, the larger DL will result in shallower NP (see

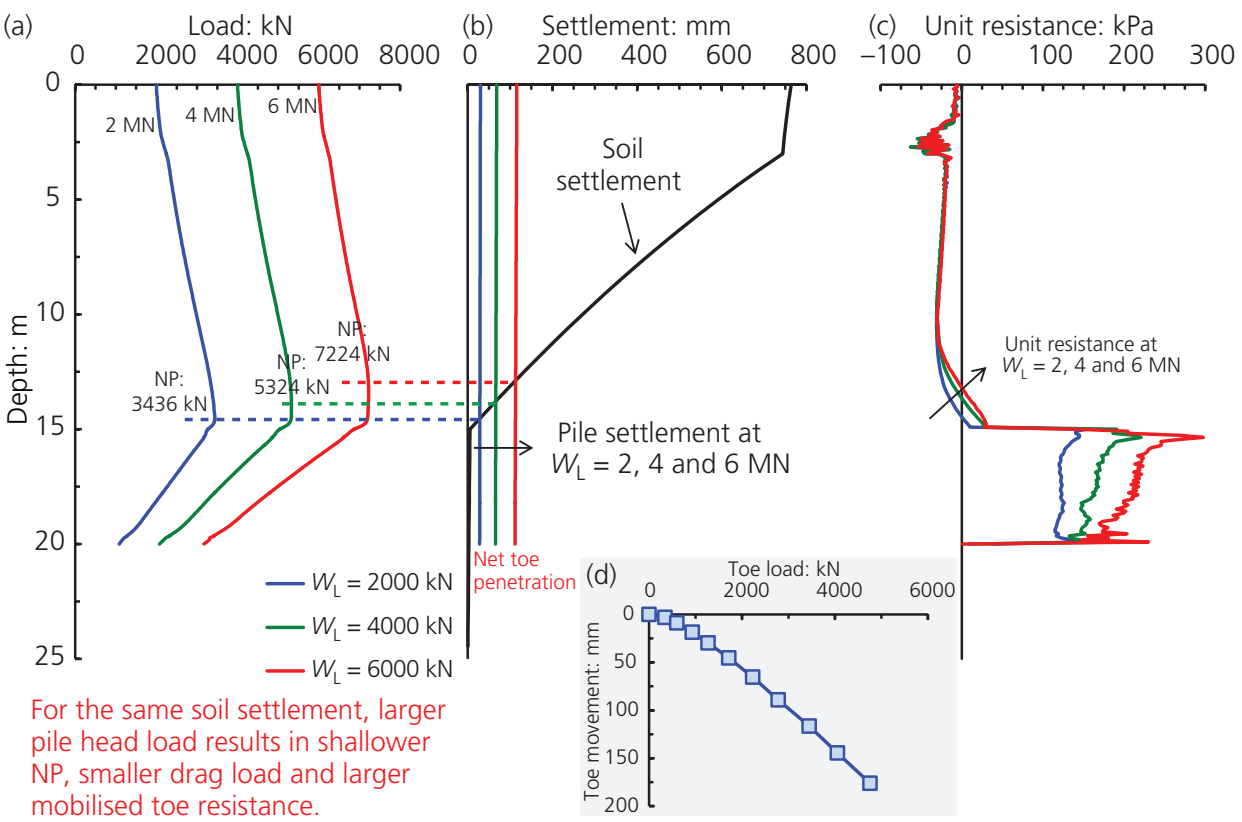

Figure 5. Cases of 2, 4 and $6 \mathrm{MN}$ DL with ground loads $40 \mathrm{kPa}$ (ground settles at $800 \mathrm{~mm}$ ) 
Figures 5(a) and 5(b)) with smaller NSF drag force (Figure 5(a) at $\mathrm{NP}$ ), larger mobilised toe resistance (Figure 5(a) at $20 \mathrm{~m}$ depth) and, hence, larger toe penetration resulting in larger pile settlements (Figure 5(b)). Figure 5(c) shows the positions of zero unit skin friction consistent with the rising NP as the DL is increased. It is obvious from Figure 5(d) that the mobilised toe resistance increased with increased DL, leading to larger toe penetrations.

One very significant finding of these studies is shown in Figure 6. The results suggest that the toe penetration load movement response is unique and that it can be obtained from either applying various DLs on the pile head like in a short-term pile load test or, alternatively, it is also the same response in an 'impossible'-toperform long-term simulated pile loading test by inducing different amounts of ground settlements instantly around the pile. But these very important test data can actually be easily obtained from shortterm instrumented pile loading tests using the Hanifah and Lee (2006) global strain extensometer system of measuring the toe loads together with the toe movements in the pile loading test for the loads applied to the pile head, as required for ultimate (or preliminary) instrumented pile tests commonly used in Singapore.

For the case of slow consolidation settlements of soft clays with time, the typical development of NSF over time is shown in Figures 7(a)-7(c). It is observed that as the NP moves downwards, drag forces and mobilised toe resistances increase, as do the pile settlements over time along with the progress of the soft clay consolidation and ground surface settlements over time. The significance of the results is that the magnitude of NSF drag loads is a function of amount of ground settlements. This is in particular important to pile design, in particular, when there are situations of matured reclaimed land soft grounds with relatively small amounts of ongoing residual consolidation settlements at the time of new pile installations, typical of commercial developments in much of reclaimed lands sites on Singapore.

Simulated loading tests of the same pile subjected to varied amounts of drag forces and different amounts of ground settlements are shown in Figure 8. The results showed clearly that drag forces do not affect the geotechnical capacity of the piles, defined as the peak resistance of the tested pile to failure. Of course, the pre-loading imposed by the drag force will result in a tendency of the pile to appear stiffer to an applied load - actually, a beneficial consequence of the buildup of the drag force.

All the load movement curves converged to a limiting value of about $6.8 \mathrm{MN}$ after about $50 \mathrm{~mm}$ pile settlements. Larger ground settlements resulted in larger drag forces and produced a softer pile response after load levels of $3.5 \mathrm{MN}$. However, the geotechnical capacity of the pile remained the same when the pile was pushed down to about $50 \mathrm{~mm}$ vertical head displacements in the simulated load tests.

Variable surcharge load cases

Variable working load cases
\begin{tabular}{|c|c|c|}
\hline $\begin{array}{c}\text { Head load: } \\
\text { kN }\end{array}$ & $\begin{array}{c}\text { Toe load: } \\
\mathrm{kN}\end{array}$ & $\begin{array}{c}\text { Toe penetration: } \\
\mathrm{mm}\end{array}$ \\
\hline 2000 & 1180 & 27.99 \\
\hline 4000 & 2241 & $65 \cdot 27$ \\
\hline 6000 & 3431 & 111.58 \\
\hline
\end{tabular}

\begin{tabular}{|c|c|c|}
\hline $\begin{array}{c}\text { Surcharge: } \\
\mathrm{kPa}\end{array}$ & $\begin{array}{c}\text { Toe load: } \\
\mathrm{kN}\end{array}$ & $\begin{array}{c}\text { Toe penetration: } \\
\mathrm{mm}\end{array}$ \\
\hline 10 & 1704 & $44 \cdot 38$ \\
\hline 20 & 1951 & $53 \cdot 42$ \\
\hline 40 & 2241 & $65 \cdot 27$ \\
\hline
\end{tabular}

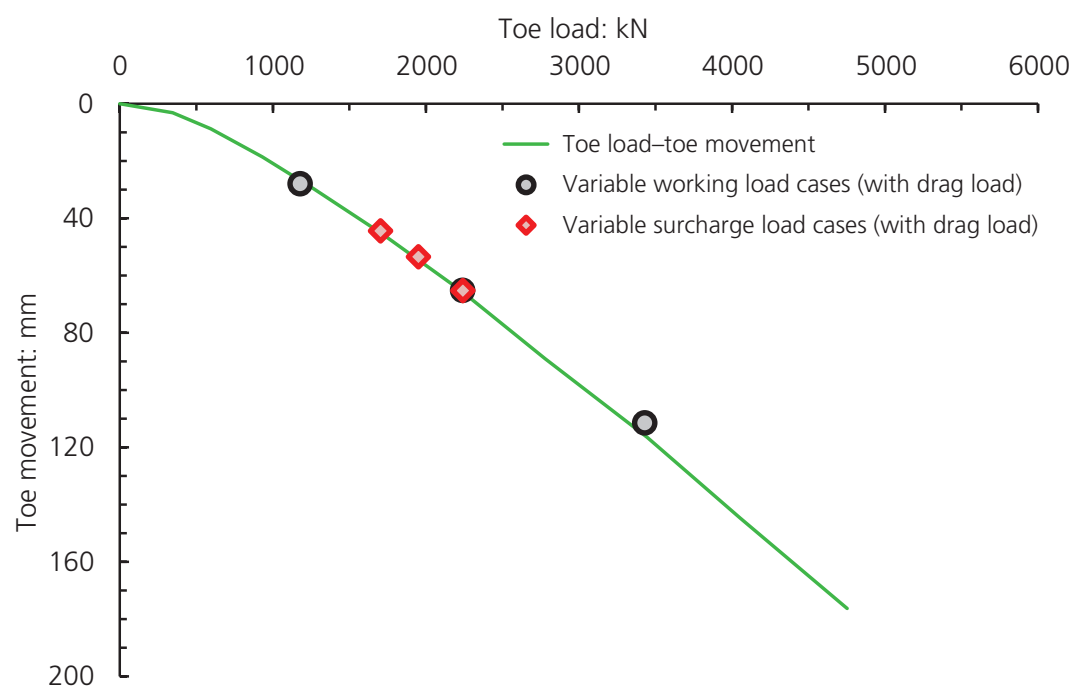

Figure 6. Toe penetration resistances obtained from variable head

loads (short-term pile load tests) cases and variable ground

settlements cases (long-term FEM-simulated pile load tests) 


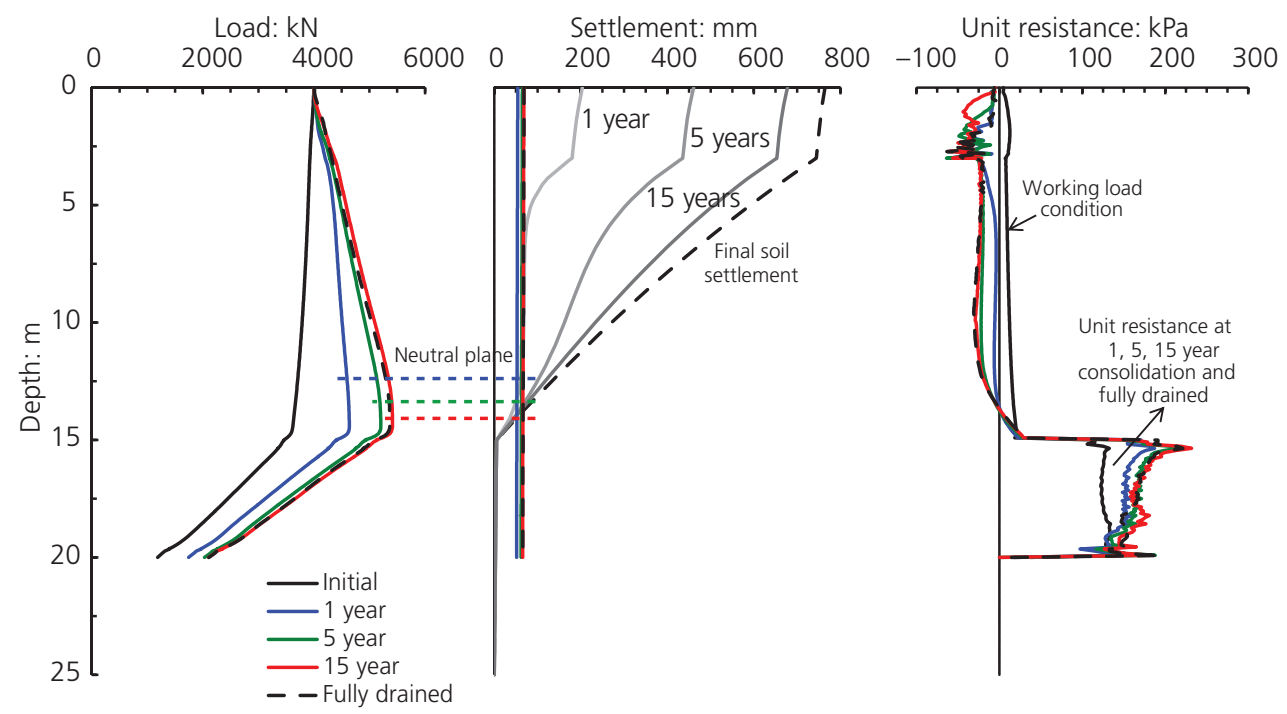

Figure 7. Pile subjected to increasing NSF over time as soil consolidates

If the piles were coated with bitumen to nullify the drag forces above the soft clay base, the piles would respond in slow loading tests as in Figure 9.

This is modelled by setting the interface friction factor to $0 \cdot 1$ ( $10 \%$ of soil shear strengths) along the fill and the soft clay layers in the single pile FEM model. The effect of the bitumen coating is to eliminate the drag forces, but it also reduced the geotechnical capacity of the pile from 6.8 to $5.6 \mathrm{MN}$ at $50 \mathrm{~mm}$ vertical pile head displacements.
Plaxis FEM model of pile groups with NSF loadings

It has been reported that NSF drag forces in pile groups is somewhat reduced due to the effects of the outer piles on the inner piles, as the drag force on inner piles are limited by the weight of soils between the piles. A field experiment reported by Okabe (1977) showed the measured response of these piles as in Figure 10.

Similar findings had been observed in centrifuge tests reported by Lam et al. (2013), with measured responses on piles at different

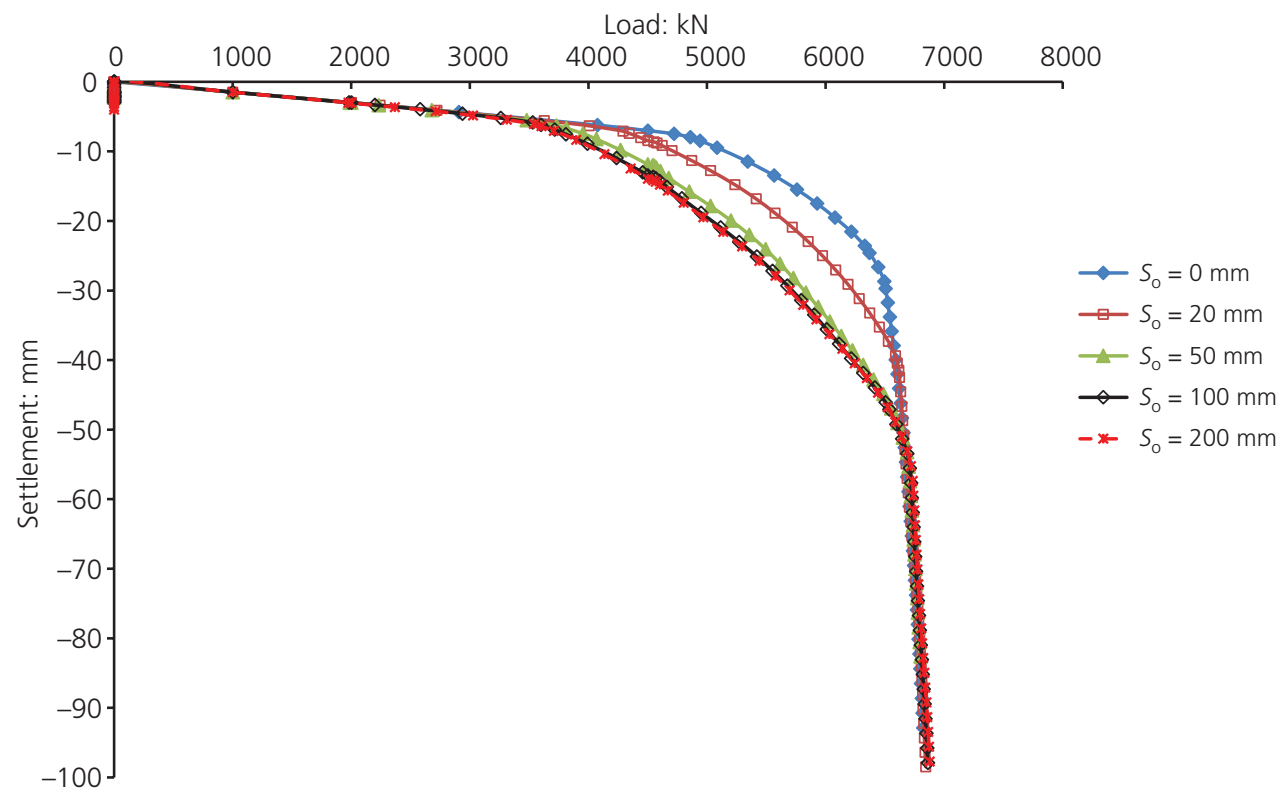

Figure 8. Simulated load tests on the same pile with varied NSF drag loads from increasing amount of ground settlements 


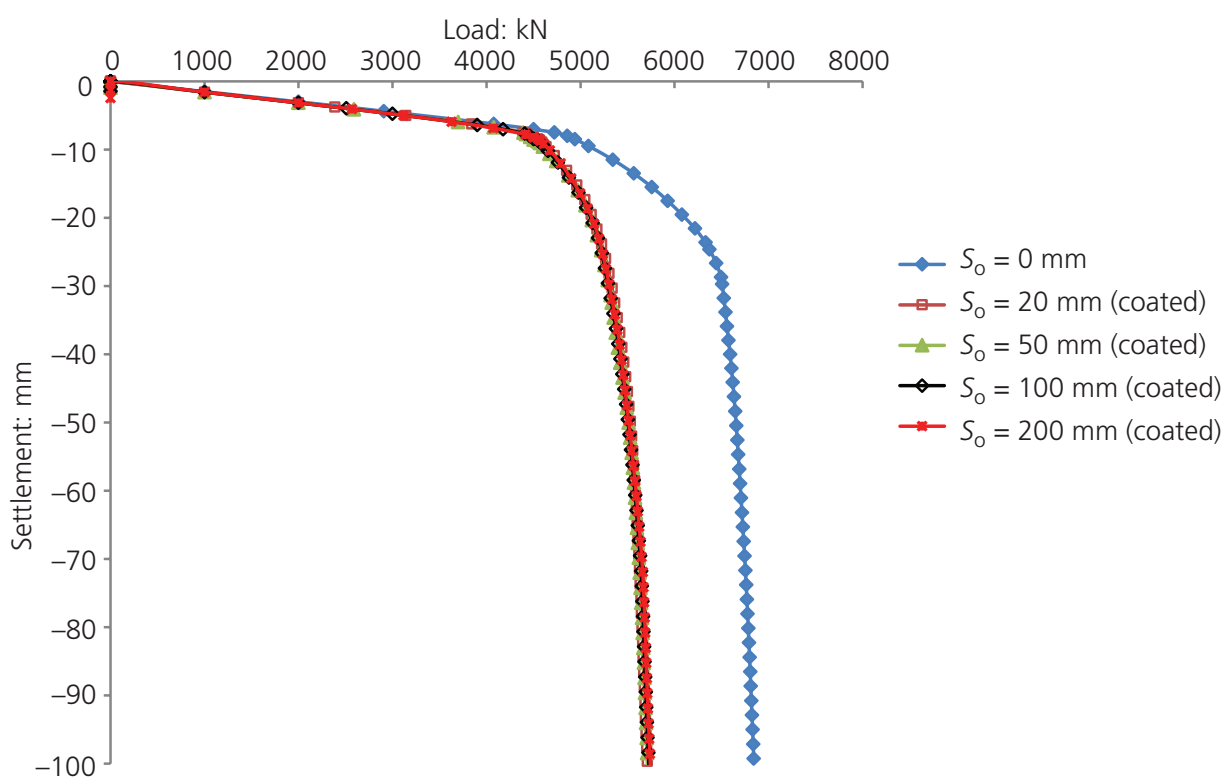

Figure 9. Load tests on bitumen-coated pile with varied amounts of ground settlements (NSF drag force is eliminated)

locations of a pile group shown to occur for the inner piles, with reduced drag forces in a consolidating ground.

Such results, showing reduction of drag force on inner piles, can also be replicated in a 3D FEM model study of a wide pile group similar to the single pile study as shown in Figure 11. The piles and soil model parameters and stratigraphy adopted for the 3D FEM model is the same as the single pile study in Figure 1. It is obvious that the pile group with a rigid pile cap must settle as a single entity. Thus, the NP for the pile group must be nearly at the same level somewhere above the pile toes.

The FEM pile group behaviour agrees very well with the observed results in the field experiments as well as the centrifuge tests. In general, the centre piles experienced the largest reduction effects than for the piles located towards the edge of the group. The corner piles will experience the largest drag forces. These effects may be exploited for design of large pile groups and pile rafts in settling grounds, when the amount of reduced drag forces can be determined approximately in a 3D FEM model, using coupled consolidation deformation analysis (soil deformation and consolidation process are fully interactive in the FEM computations). However, to use these sacrificial outer piles as a means of reducing drag forces on interior piles is a very expensive proposition, and unnecessary when designed correctly.

This mechanism for the shielding effects in closely spaced pile groups can be explained by the recognition that the significant finding of the single pile study, that is, the magnitude of the induced drag forces, is a function of the relative amount of settlements of the ground with respect to the piles. In the closely
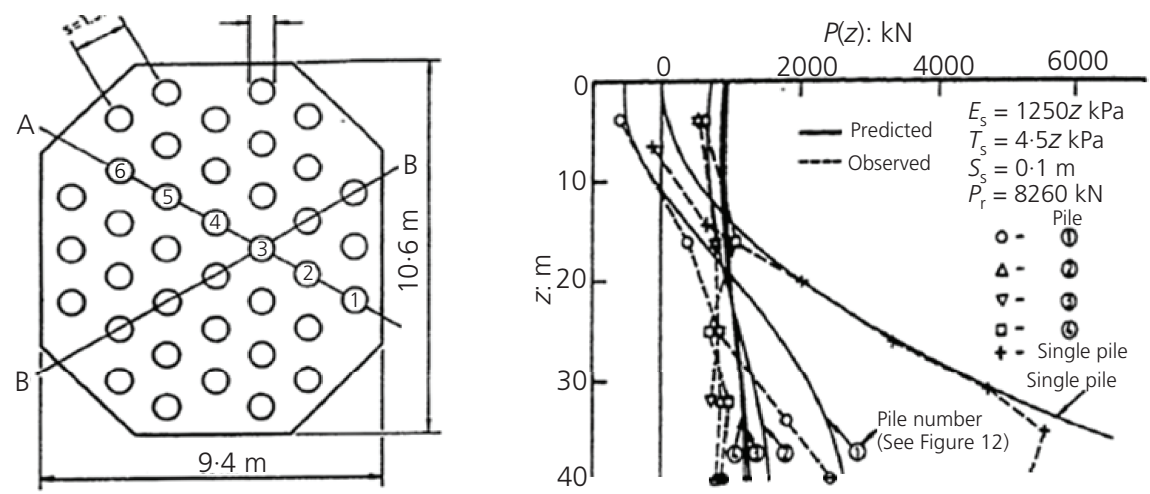

Figure 10. Field experiments of pile group subjected to NSF (Okabe, 1977) 


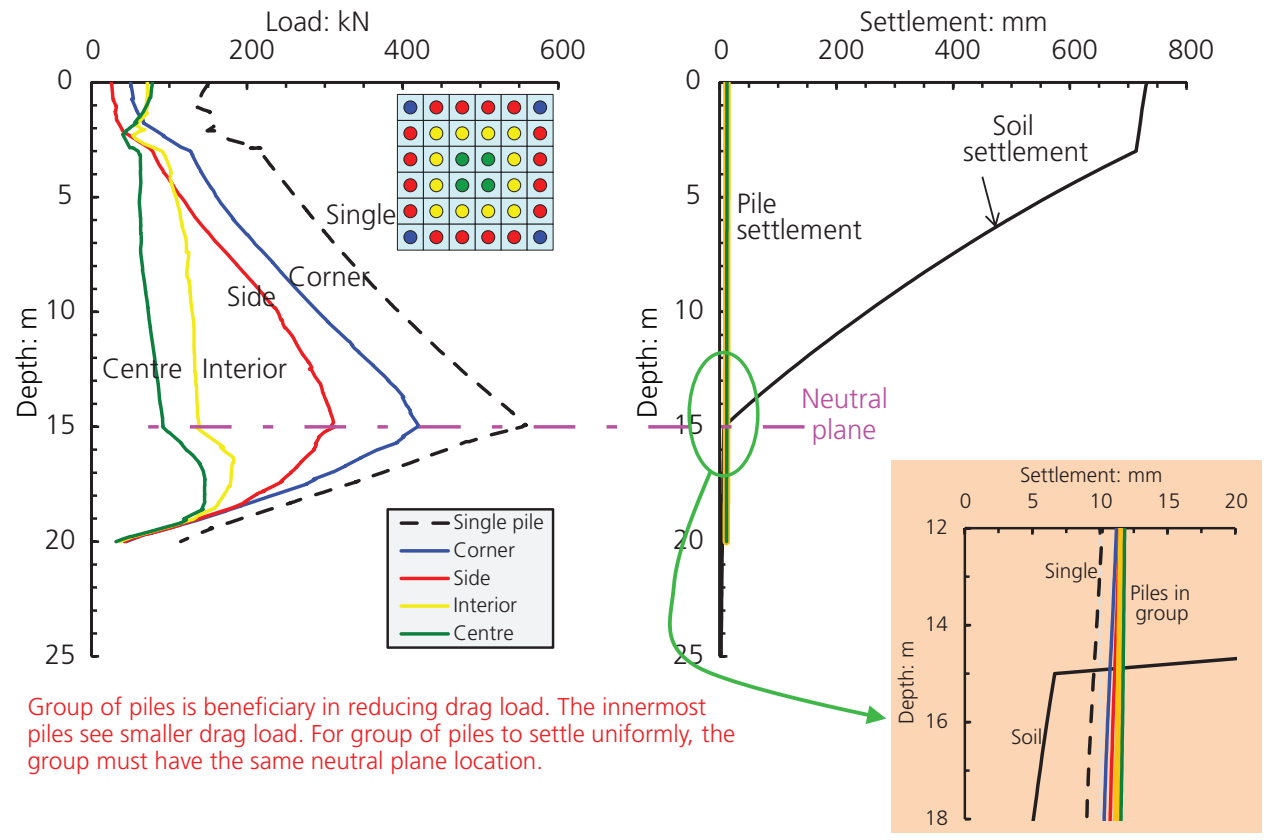

Figure 11. Plaxis 3D FEM results of a large $(6 \times 6)$ pile group in settling ground

spaced pile groups, the piles essentially moved as a block relative to the settling ground. Thus, the outermost piles experience full NSF development due to the settling ground, while the inner piles experience much less relative ground settlements as a function of pile position relative to the group perimeter.

\section{Conclusions}

A review of the design of piles with NSF when subjected to settling ground conditions from the consolidation of soft clays had been presented. Based on the review, a detailed FEM study of piles in a settling ground had been conducted.

The following conclusions are inferred.

(a) Codes like BS EN 8004:1986 and CP4 incorrectly treat drag forces as external unfavourable actions that reduce the pile geotechnical capacity.

(b) EC7 also treats drag forces as an external unfavourable action. However, it also recognised that when the remaining ground settlement is relatively small as in a matured or treated (with vertical drains and pre-loading) recent reclaimed land, this approach will be too conservative for pile design. Therefore, it allows the designer to treat the expected ground settlement as the geotechnical action and design for much smaller drag forces to be determined by a rigorous soil/pile interaction analysis. Such analysis is described in the Fellenius unified design method. It can also be done efficiently with a geotechnical FEM analysis.

(c) The key finding of the single pile FEM study is that the induced NSF drag force is a function of the ground settlement relative to the pile. For small settlements, the induced NSF force may be much less than the simplistic full skin friction analysis.

(d) The alternative is to use full 3D FEM models to include the effects of settling soil on the pile response to obtain a more realistic estimate of the NSF drag forces and the settlements of the pile and the ground.

(e) In the case of large pile groups in settling ground, the added benefits of the reduction of drag force on the inner piles may be estimated properly by a 3D FEM model analysis of the group. Thus, the reduced drag forces on the inner piles can be computed and used for a more economical design of the pile groups, from a structural loading point of view.

$(f)$ It should be well noted that NSF problem is not one of geotechnical capacity. Rather, it is one of a serviceability limit state, where after establishing the NP, the pertinent question is whether the pile foundation settlements will remain small and within acceptable limits or not.

\section{REFERENCES}

BSI (1986) BS EN 8004:1986: Code of practice for foundations.

BSI, London, UK.

BSI (2004) BS EN 1997-1:2004: Eurocode 7. Geotechnical design. General rules. BSI, London, UK.

Fellenius BH (1984) NSF and settlement of piles. Proceedings of the Second International Seminar, Pile Foundations, Nanyang Technological Institute, Singapore.

Fellenius BH (1988) Unified design of piles and pile groups. Transportation Research Record 1169: 75-82. 
Geotechnical Research

Volume 3 issue 4
Negative skin friction pile concepts with

soil-structure interaction

Tan and Fellenius
Fellenius BH (2015) The Red Book - Basics of Foundation Design. See http://www.fellenius.net (accessed 10/11/2016). Hanifah AA and Lee SK (2006) Application of global strain extensometer (GloStrExt) method for instrumented bored piles in Malaysia. Proceedings of the DFI-EFFC 10th International Conference on Piling and Deep Foundations, May 31-June 2, Amsterdam, the Netherlands, pp. 1-8.

Lam SY, Ng CC and Poulos HG (2013) Shielding piles from downdrag in consolidating ground. Journal of
Geotechnical and Geoenvironmental Engineering 139(6): 956-968.

Okabe T (1977) Large negative friction and friction-free piles methods. Proceedings of the 9th International Society for Soil Mechanics and Geotechnical Engineering, Tokyo, Japan, 11-15 July, vol. 1, pp. 679-682.

Spring Singapore (2003) CP4:2003: Code of practice for foundations. Spring Singapore, Singapore.

\section{HOW CAN YOU CONTRIBUTE?}

To discuss this paper, please submit up to 500 words to the editor at journals@ice.org.uk. Your contribution will be forwarded to the author(s) for a reply and, if considered appropriate by the editorial board, it will be published as a discussion in a future issue of the journal. 